\title{
Young carers: growing up with chronic illness in the family - a systematic review 2007-2017
}

\author{
Nino Chikhradze*, Christiane Knecht and Sabine Metzing
}

\begin{abstract}
Background: Young carers are children or young people who look after family members who are ill or have disabilities. They take over similar caregiving responsibilities to those of adult family carers and need special support. The purpose of this literature review was to summarize the body of knowledge about young carers' lives with a special focus on their personal experiences, impact of caring, needs and coping behaviors.

Method: A systematic review was carried out, including quantitative and qualitative studies as well as reviews published in English or German. The following databases were searched: Cinahl, Embase ${ }^{\varpi}$, PubMed ${ }^{\varpi}$, Gesis sowiport, ERIC ${ }^{\oplus}$, Cochrane Library, Pubpsych, PsychArticles (1/2007 to 6/2017). The Critical Appraisal Skills Programme (CASP) and the methodology checklist NICE were used to assess the literature.

Results: After appraisal, 25 studies which considered young carers between four and 25 years of age were included. Studies reported that many children in families with chronically ill members are highly involved in caring. Due to this responsibility, they spend most of their time at home. Although the caregiving experiences are pervasive, the children conceal the conditions of their relatives from others. They also do not want to be identified as young carers. Thus, their social experiences are limited. These children or adolescents would like to live a "normal live". They prioritize their family member's needs over their own. They would like professional support, which recognizes the real needs of their family members.

Conclusions: This systematic review shows that since 2007 the situation of affected children and adolescents has achieved an important place in international research and also in German-language countries. Based on the included studies, it has been possible to identify theoretical models that help to describe and explain the phenomenon of young carers. In order to provide appropriate support and interventions, it is of importance for the professionals to know and consider that a family-oriented perspective is vital.
\end{abstract}

Keywords: Young carers, Children as caregivers, Chronic illness/disability, Parental illness, Children of impaired parents

\section{Background}

Children and adolescents under the age of 18 who provide care, assistance or support for one or more chronically ill family members are called young carers [1].

According to a former comprehensive review $[2,3]$, these children provide help and care at any age, and the amount of their tasks increases with age. There is a wide range of young carers' duties described in the literature.

\footnotetext{
*Correspondence: Nino.chikhradze@uni-wh.de

School of Nursing Science, Faculty of Health, Witten/Herdecke University Faculty of Health School of Nursing Science, Stockumer Straße 10, 58453 Witten, Germany
}

(c) The Author(s). 2017 Open Access This article is distributed under the terms of the Creative Commons Attribution 4.0 International License (http://creativecommons.org/licenses/by/4.0/, which permits unrestricted use, distribution, and reproduction in any medium, provided you give appropriate credit to the original author(s) and the source, provide a link to the Creative Commons license, and indicate if changes were made. The Creative Commons Public Domain Dedication waiver (http://creativecommons.org/publicdomain/zero/1.0/) applies to the data made available in this article, unless otherwise stated. care; in summary it can be stated that they do the same as adult informal carers. However, a common categorical system could not be identified, which makes comparison between study findings difficult. The extent of their help varies and depends on many factors, i.e. the severity of the chronic illness, family constellation, the family's economic and emotional deprivation, lack of outside support and the process of being socialized into care. More than half of young carers live with single mothers who predominately suffer from chronic somatic diseases. Positive as well as negative effects are described 
in the literature: young carers show an increased sense of self-esteem, early maturity, a close relationship towards their parents and some feel well prepared for life. Negative impact relates to the children's physical, psychosocial and educational situation and further development $[2,3]$.

According to the British census from 2011, the prevalence of young carers between five and 17 years of age is 2.1\% for England and Wales [4]. Nagl-Cupal et al. [5] also identified relevant extrapolations from the USA, Australia and New Zealand, in which the (estimated) prevalence rates range from $3.2 \%$ up to $4.2 \%$. However, the basic population in these surveys varied considerably according to the age of participants, which again makes comparisons difficult. A representative Austrian survey with school pupils identified a prevalence rate of $4.5 \%$ for children between ten and 14 years [5]. Projections for the age span between five and 18 years for Austria indicated a rate of $3.5 \%$. Becker [6] showed rising numbers of young carers worldwide in his presentation during the 2nd Young Carers Conference "Every child has the right to...", hosted in Malmö this year. He estimated prevalence rates varying between 2 and $8 \%$ in selected European and transatlantic countries. To date, comparable data for Germany is missing. Corresponding to other countries young carers in Germany remain a hidden population that is hardly perceived in the societal awareness.

For this reason, the German Federal Ministry of Health put out a prevalence study among school pupils in Germany to gain more insight into young carers' everyday life. In preparation of this survey and since the above-mentioned literature review was published in 2007 [2, 3], we carried out an updated literature study which is the object of the present contribution.

\section{Method}

The method we decided on for this literature study was a systematic review. As we intended to gain an explorative and comprehensive overview on the existing knowledge concerning young carers, we made this decision in order to include studies of all designs [7] (qualitative and quantitative ones) as well as literature reviews written in English or German. All available studies were systematically identified according to explicit methods, selected, and critically appraised; the findings were extracted, listed descriptively and summarized. Everything was based on the existing standards of Higgins and Green [8].

The overall aim is to summarize the body of knowledge about young carers' lives with a special focus on their personal experiences, needs, coping behaviors and impact of caring in order to raise awareness of these children's everyday life and to develop compassion in society towards this phenomenon. Thus, we aim to answer the following general question with focal and operationalized sub-questions:

What are the personal experiences of children and adolescents caring for a chronically ill family member?

- What are the characteristic attributes of young carers?

- Which factors lead to children and adolescents becoming young carers?

- What influence does a chronic illness in the family have on the lives of involved children?

- How do affected children cope with the demands of a chronic illness in the family?

- What needs do affected children have and how do they express these?

\section{Literature search}

The literature search was conducted in the following databases: CareLit $^{\oplus}$, Cinahl, Embase ${ }^{\oplus}$, PubMed ${ }^{\oplus}$, Gesis sowiport, PBSC, ERIC ${ }^{\oplus}$, Healthstar ${ }^{\oplus}$, Cancerlit ${ }^{\oplus}$, PsycINFO $^{\circ}$, psyndex trial $^{\circ}, \mathrm{SOSIG}^{\oplus}$ and Cochrane Library and included studies published from January 2007 to June 2017. The following keywords were used in various combinations: young carers, young caregivers, family caregivers, children as caregivers, chronically ill parents, children of impaired parents. As mentioned before, studies of all designs as well as reviews that passed the critical appraisal and gave answers to our questions were included. These studies concerned children and adolescents between the age of four and 18 years. This age span was extended only for studies from Australia, since the definition in that country includes young adults up to the age of 25 [9]. Publications focusing on young adult carers and/or siblings were excluded, as were readers' letters, editorials, pictorials and studies with methodological and ethical discourses. Publications e.g. from Africa, Thailand, China, Japan and Korea were excluded, since the cultural differences were considered to be too great and hardly comparable. Figure 1 presents the search strategy used and the hit rates of the results in the literature search.

\section{Data extraction and quality assessment}

Qualitative assessment review instruments were used to extract the characteristics of the remaining studies. The quality evaluation of the qualitative studies and the literature review was conducted with the Critical Appraisal Skills Programme [10]. Using the "Quality appraisal checklist - quantitative studies reporting correlations and associations" of the National Institute for Health and Clinical Excellence (NICE) public health guidance [11], we were able to assess the quantitative studies. For the classification (rating) of all studies the criteria of the NICE [11] method $(++,+,-$, NA, NR) were applied (Tables 123456 ). A score higher than or equal to $70 \%$ 


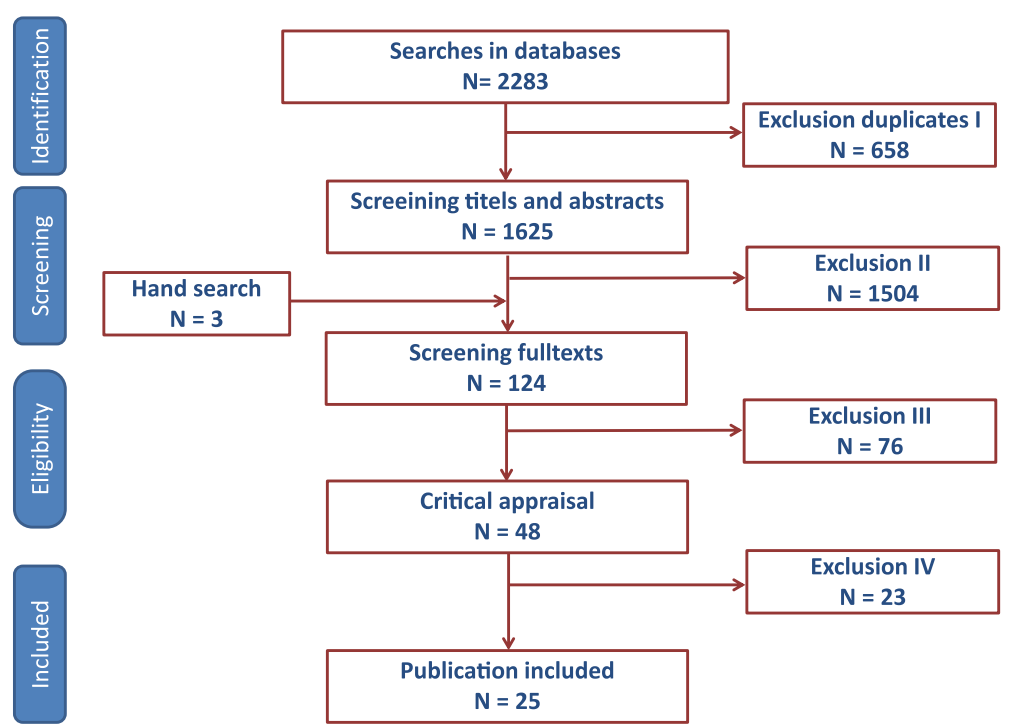

Fig. 1 Flow diagram of study selection process

out of all of points was considered as high quality. It should be noted that this score was not based on literature, as there is no literature describing what should be considered a high or low methodological quality score.

Two researchers carried out the methodological steps parallel: literature search, data extraction and quality evaluation; the results of these steps and any ambiguities or uncertainties were discussed with a third member of the research group and then summarized.

\section{Data analysis}

Data analysis was carried out thematically and interpretively according to our research questions. In a first step, all the publications included were coded openly. Emerging themes were identified and matched with similar ones (topics). In the next step, these topics were thematically structured in concepts in a categorical system using the software program MAXQDA. Finally, we were able to synthesize all of the publications [7]. The analysis was conducted by two master graduates and a senior researcher.

\section{Results}

The systematic search resulted in 2283 publications being found. After rejecting the duplicates, screening the remaining titles and abstracts and applying to the inand exclusion criteria, 48 publications were subjected to a critical appraisal. Of these 25 studies were finally included in the review (Fig. 1).

Tables 123456 show a differentiated picture of all the publications considered.

Analogous to our questions addressed at the literature five content categories were formed:
1. Characteristic values of young carers

2. How children become caregivers

3. Impact of caring on the children

4. Needs

5. Coping actions

These categories are described in the following.

\section{Characteristic values of young carers}

New study results confirm the existing knowledge about characteristics of young carers according to age, gender, family constellation, care recipients and variety of caring tasks, as summarized in the former literature review from Metzing \& Schnepp [2, 3].

Children in single households are still more likely to be involved in caregiving than children whose parents live together [12-14]. Study findings also confirm that care is provided for chronically ill mothers in the majority of cases [5, 15]; the results on this aspect vary between 67 and 75\% [12,13,16-20]. Apart from the mothers, it is often the grandmother who receives care from young carers, followed by chronically ill siblings. Less often do young carers care for male members of the family $[5,15,21]$.

If children are involved in caring, it can take up a lot of time in their childhood. In a qualitative study, 50 children between the ages of nine and 22 stated that they were involved in helping in their family for "710 years", "more than 10 years" or "all the time" [22]. The results presented by Nagl-Cupal et al. [5] also show the enormous amount of time that young carers spend on supporting their families; they identified great differences between non-caregiving and caregiving children in 
Table 1 Characteristics of qualitative studies.

\begin{tabular}{|c|c|c|c|c|}
\hline N & References & Aim & Sample & Setting, data collection and analysis \\
\hline 1. & $\begin{array}{l}\text { Moore and McArthur } \\
\text { (2007) } \\
\text { Australia }\end{array}$ & $\begin{array}{l}\text { To identify the current needs and } \\
\text { barriers to services for young carers } \\
\text { and their families }\end{array}$ & $\begin{array}{l}\text { Convenience sampling: } \\
\text { Young carers } n=50 \\
(\mathrm{~F} n=24 ; M n=26) \\
\text { Age: } 9-24 \\
\text { Care recipient: parents }\end{array}$ & $\begin{array}{l}\text { Setting: NR } \\
\text { Semi-structured, face-to-face interviews: } \\
\text { Participatory approach with peer researchers } \\
\text { Content analysis }\end{array}$ \\
\hline 2. & $\begin{array}{l}\text { Earley et al. (2007) } \\
\text { UK }\end{array}$ & $\begin{array}{l}\text { To explore young carer's appraisals } \\
\text { of the impacts of caregiving and } \\
\text { the ways they cope with these } \\
\text { demands }\end{array}$ & $\begin{array}{l}\text { Convenience sampling: } \\
\text { Young carers } n=17 \\
\text { (F } n=3 ; \mathrm{M} n=14 \text { ) } \\
\text { Age: } 10-16 \\
\text { Care recipient: siblings } \\
n=8, \text { parents } n=8, \\
\text { grandparent } n=1\end{array}$ & $\begin{array}{l}\text { Setting: two locations of supporting projects } \\
\text { for young carers } \\
2 \text { focus group interviews with } 9 \text { und } 8 \\
\text { adolescents; } 3 \text { semi-structured interviews } \\
\text { with female participants; } \\
\text { Thematic analysis }\end{array}$ \\
\hline 3. & $\begin{array}{l}\text { Bolas et al. (2007) } \\
\text { UK }\end{array}$ & $\begin{array}{l}\text { To explore the personal } \\
\text { experiences of young carers } \\
\text { in relation to their well-being }\end{array}$ & $\begin{array}{l}\text { Convenience sampling: } \\
\text { Young carers } n=5 \\
(\text { F } n=3 ; M n=2) \\
\text { Age: } 14-18\end{array}$ & $\begin{array}{l}\text { Setting: at home or at the young carer's } \\
\text { centre } \\
\text { Semi-structured interviews } \\
\text { Interpretative phenomenological analysis }\end{array}$ \\
\hline
\end{tabular}

4. Metzing (2007)

5. Metzing and Schnepp (2008) Germany

6. Kain (2009) USA

7. Moore and McArthur (2009) Australia

8. McDonald et al. (2009) New Zealand

9. Richardson et al. (2009) UK

10. Svanberg et al. (2010) UK

11. Nichols et al. (2013) Canada

12. Doutre et al. (2013) UK
Qualitative evaluation of a young carers' initiative

To gain insight into the situation of young carers and their families in order to provide a basis for the concept of family oriented support

To identify and describe the basic social psychological problem shared by young adolescent girls

To gather young carers' views about school, the challenges they face in engaging with education and their peers

To explore experiences of both young carers and those they support

To discover the experiences of the children of younger people with dementia.

To learn more about the needs and experiences of young carers of parents with frontotemporal dementia

To explore the experiences of young carers from a strengths-based perspective
Care recipient: sibling,

parent, stepfather

Theoretical Sampling:

Families $n=34$, Young

carers $n=41$

$(\mathrm{F} n=25 ; \mathrm{M} n=16)$

parents $n=41$

Care recipient: parents,

siblings, grandparents

Theoretical Sampling:

Young carers $n=9$

$(\mathrm{F} n=9)$

Age: 11-14

Care recipient: grandparents, parents, others

Convenience sampling:

Young carers $n=51$

$(\mathrm{F} n=29 ; \mathrm{M} n=22)$

Age: 12-21

Care recipient: family members

Convenience sample:

Young carers $n=14$

$(\mathrm{F} n=12 ; \mathrm{M} n=2)$

Age: 11-26

Care recipient: parents,

siblings, grandparents

Convenience sampling:

Young carers $n=24$

$(\mathrm{F} n=12 ; \mathrm{M} n=12)$

Age: 11-16

Care recipient: siblings,

parents,

Convenience sampling:

Young carers $n=12$

$(F n=6 ; M n=6)$

Age: 11-18

Care recipient: parents

$(\mathrm{F} n=2 ; \mathrm{M} n=7)$

Convenience sample:

Young carers $n=14$

$(F n=10 ; M n=4)$

Age: 11-18

Care recipient: parents

Convenience sample:

children, who were accompanied 3 semi-structured interviews and photo

more than two years in a
Setting: the interview appointments and locations were chosen by the families mostly at home

Semi-structured interviews

Grounded Theory

Setting: the interview appointments and locations were chosen by the families at home Semi-structured interviews Grounded Theory

Setting: interviews by phone and a group interview 51 interviews: semi-structured interviews $n=44$ and a group interview

Data analysis: NR

Setting: NR

Semi-structured interviews (if possible: together with the supported ill family member)

Grounded Theory

Setting: the location of supporting project for young carers

3 focus group discussions

Thematic content analysis

Setting: the interview locations were chosen by the young carers- at home

Semi-structured interviews

Grounded Theory - Constant comparative methods and analysis carried out cyclically

Setting: interviews via telephone und Skype Semi-structured focus group interviews Descriptive thematic analysis

Setting: at school

elicitation techniques with 7 young carers 
Table 1 Characteristics of qualitative studies. (Continued)

\begin{tabular}{|c|c|c|c|c|}
\hline$N$ & References & Aim & Sample & Setting, data collection and analysis \\
\hline & & & $\begin{array}{l}\text { Young carers support project } \\
n=6(\mathrm{~F} n=3 ; \mathrm{M} n=3) \\
\text { Age: } 11-13 \\
\text { Care recipient: parents }\end{array}$ & Interpretative, phenomenological analysis \\
\hline 13. & $\begin{array}{l}\text { Ortner (2014) } \\
\text { Austria }\end{array}$ & $\begin{array}{l}\text { To understand the life of } \\
\text { children, who grow up with } \\
\text { a mental ill parent }\end{array}$ & $\begin{array}{l}\text { Convenience sample: } \\
\text { Young carers } n=9 \\
\text { (F } n=6 ; \mathrm{M} n=3) \\
\text { Age: } 13-24 \\
\text { Care recipient: parents }\end{array}$ & $\begin{array}{l}\text { Setting: NR } \\
9 \text { qualitative interviews } \\
\text { Grounded Theory }\end{array}$ \\
\hline $\begin{array}{l}14 . \\
15 .\end{array}$ & $\begin{array}{l}\text { Großmann (2015) } \\
\text { Germany } \\
\text { Mauseth \& Hjälmhult } \\
\text { (2016) } \\
\text { Norway }\end{array}$ & $\begin{array}{l}\text { To identify the needs and } \\
\text { relevance for supporting } \\
\text { young carers }\end{array}$ & $\begin{array}{l}\text { Convenience sampling: } \\
\text { Experts } n=3, \\
\text { Young carers } n=11 \\
\text { ( } \mathrm{F} n=6 ; \mathrm{M} n=5) \\
\text { Age: } 7-13 \\
\text { Care recipients: parents } \\
\text { Theoretical Sampling: } \\
\text { Adolescents } n=15, \\
(\mathrm{~F} n=8 ; \mathrm{M} n=7 \text { ) } \\
\text { Care recipient: parents } \\
\text { with multiple sclerosis } \\
\text { disease }\end{array}$ & $\begin{array}{l}\text { Setting: the location of supporting project } \\
\text { for young carers in Germany (YCD) } \\
3 \text { expert interviews, } 11 \text { problem-centred, } \\
\text { semi-structured interviews } \\
5 \text { focus group interviews } \\
\text { content analysis } \\
\text { Setting: The interviews took place in a quiet } \\
\text { setting without disruptions, in the family } \\
\text { home or a convenient office nearby. } \\
\text { Semi-structured interviews } \\
\text { Grounded Theory }\end{array}$ \\
\hline
\end{tabular}

the category "[help] more than 5 hours daily". Young carers have no freedom of choice about the tasks they take on at home $[17,23]$. The amount of these tasks depends on the care and support needed, and varies according to the course of the disease and the stress involved [13, 15, 19, 24]. According to the Austrian school survey [5], 15\% of the children and young carers are very often completely on their own with their caregiving duties. However, slightly less than a third (31\%) also stated that they share their duties with a healthy parent. Sharing the responsibility with a healthy sibling is more seldom the case (17.1\%). These findings also showed a significantly higher percentage of girls as caregivers $(69.8 \%)$ in comparison with non-caregivers girls

Table 2: Methodological quality of qualitative studies ${ }^{a}$ - CASP Checklist

\begin{tabular}{|c|c|c|c|c|c|c|c|c|c|c|c|c|c|c|c|}
\hline Screening Questions & 1 & 2 & 3 & 4 & 5 & 6 & 7 & 8 & 9 & 10 & 11 & 12 & 13 & 14 & 15 \\
\hline \multirow[t]{2}{*}{ 1. Was there a clear statement of the aims of the research } & + & + & + & + & + & + & + & + & + & + & + & + & + & + & + \\
\hline & + & + & + & + & + & + & + & + & + & + & + & + & + & + & + \\
\hline \multirow[t]{2}{*}{ 2. Is a qualitative methodology appropriate? } & + & + & - & + & + & + & + & + & + & + & + & + & + & + & + \\
\hline & + & + & & + & + & + & + & + & + & & + & + & & + & + \\
\hline \multicolumn{16}{|l|}{ Detailed questions } \\
\hline \multirow[t]{2}{*}{ 3. Was the research design appropriate to adress the aims of the research? } & + & + & + & + & + & + & + & - & + & + & + & + & + & + & + \\
\hline & + & & + & + & + & + & + & & + & + & + & + & + & + & + \\
\hline \multirow[t]{2}{*}{ 4. Was the recruitment strategy appropriate to the aims of the research? } & + & - & + & + & - & + & + & + & - & + & - & + & + & + & + \\
\hline & + & & + & + & & + & & + & & & & + & & + & \\
\hline \multirow[t]{2}{*}{ 5. Was the data collected in a way that addressed the research issue? } & + & + & + & + & + & + & + & - & + & + & + & + & + & + & + \\
\hline & & & + & + & + & + & & & + & & & & & + & + \\
\hline \multirow{2}{*}{$\begin{array}{l}\text { 6. Has the relationship between researcher and participants been adequately } \\
\text { considered?? }\end{array}$} & + & + & + & + & + & - & + & + & + & + & + & + & + & + & NR \\
\hline & & & + & & & & & & & & & + & & & \\
\hline \multirow[t]{2}{*}{ 7. Have ethical issues been taken into consideration?? } & + & + & + & + & + & + & + & + & + & + & NR & + & - & - & + \\
\hline & + & + & + & + & + & & + & + & + & & & & & & + \\
\hline \multirow[t]{2}{*}{ 8. Was the data analysis sufficiently rigorous? } & + & + & + & + & + & - & + & + & + & + & + & + & + & + & NR \\
\hline & & & + & + & + & & + & + & + & + & + & & & & \\
\hline \multirow[t]{2}{*}{ 9. Is there a clear statement of findings? } & + & + & + & + & + & + & + & + & + & + & + & + & + & + & + \\
\hline & + & + & + & + & + & + & + & + & + & + & + & + & + & + & + \\
\hline \multirow[t]{2}{*}{ 10. How valuable is the research? } & + & + & + & + & + & + & + & + & + & + & + & + & + & + & + \\
\hline & + & + & + & + & + & + & + & + & + & + & + & + & + & + & + \\
\hline
\end{tabular}

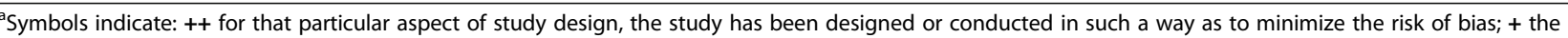
answer to the checklist question is not clear from the way the study is reported, or that the study may not have addressed all potential sources of bias for that particular aspect of study design; - Should be reserved for those aspects of the study design in which significant sources of bias may persist; NR - Not reported; NA -Not applicable 
Table 3: Characteristics of literature review

\begin{tabular}{|c|c|c|c|c|}
\hline Reference & Dataset & Aim & Search strategy & $\begin{array}{l}\text { Strategy of data analysis and the critical } \\
\text { evaluation }\end{array}$ \\
\hline $\begin{array}{l}\text { Marote et al. } \\
\text { (2012) } \\
\text { Portugal }\end{array}$ & $\begin{array}{l}\text { a total of } 21 \text { documents } \\
\text { localized were submitted } \\
\text { to critical evaluation for } \\
\text { timeframe of } 1993-2010\end{array}$ & $\begin{array}{l}\text { To undertake an integrative review } \\
\text { of studies relating to children as } \\
\text { carers, and to identify the role } \\
\text { performed by nurses along with } \\
\text { these children }\end{array}$ & $\begin{array}{l}\text { Literature reviews were } \\
\text { carried out at two points } \\
\text { during the process of } \\
\text { collection of information } \\
\text { in } 2010\end{array}$ & $\begin{array}{l}\text { The analysis of the primary studies' } \\
\text { quality considered the date and the } \\
\text { structure of publication, regarding } \\
\text { the study objectives, the methodology, } \\
\text { the results and the conclu-sions } \\
\text { obtained in each one. To this end a } \\
\text { spreadsheet was created, using } \\
\text { Microsoft Excel } 2007, \text { with the } \\
\text { extraction of information and its } \\
\text { inputting on the spreadsheet being } \\
\text { undertaken by two independent } \\
\text { evaluators. }\end{array}$ \\
\hline
\end{tabular}

(52.7\%) [5]. This gender-specific difference has proved to be statistically significant $(\mathrm{F}(1,128)=4.98, p=0.03)$ in other studies with a quantitative research design [24]. However, Lloyd [21] did not find a gender-specific difference in her sample of 4192 Irish pupils aged ten and eleven.

There is a wide spectrum of tasks and responsibilities that are taken over by children, as study results show. This includes the emotional and practical support for other members of the family [5, 14, 15, 19, 21, 23-28]. Two of the included studies developed a categorical system from their available data $[13,19]$. In her Grounded Theory study, Metzing [13] focused on the recipients of help and care to organize the inductively derived categorical system (Fig. 2). Ireland and Pakenham [19] in their study generated a multi-item scale of care tasks with the four categories "instrumental care, social/emotional care, personal/intimate care and domestic/household care" [p. 713] through factor analysis.

Table 4: Methodological quality of systematic review - CASP Checklist

\begin{tabular}{lc}
\hline A Are the results of the review valid? & 1 \\
\hline 1. Did the review address a clearly focused question? & ++ \\
2. Did the authors look for the right type of papers? & + \\
3. Were all of the important, relevant studies included?? & + \\
4. Did the review's authors do enough to assess the quality & ++ \\
of the included studies? & ++ \\
5. If the results of the review have been combined, was it \\
reasonable to do so? \\
6. What are the results? \\
7. How precise are the results? \\
C Will the results help locally? \\
8. Can the results be applied to the local population? \\
9. Were all important outcomes considered? \\
10 Are the benefits worth the harms and costs?
\end{tabular}

\section{How children become caregivers}

The process of children becoming young carers is an increasing topic in recent literature concerning young carers when compared to the previous review. Becoming a caregiver is influenced by the children's motives, the way in which they adapt to their new role and the resources available within the family itself. The following passage deals with these factors.

Although working out the motives for children taking on a caring role was not the primary aim of Metzing's study [13], it did however become clear during the analysis that the children found it quite natural to be there for the family. For them, their family comes first and foremost and, in their new role, they try to hold the family together, maintaining everyday life [5, 13, 28, 29]. Further motives for accepting the responsibility are: a good feeling in taking on caregiving and to be needed, wanting to help [5] and love [29-31]. For all of these motives, Nagl-Cupal et al. [5] were able to prove statistically significant differences between caregiving and non-caregiving children of the same age. In her qualitative study Kain [25, P.32] identifies three different ways of how the various motives are turned into active practice and how children become young carers. It should however be noted that the third way does not leave the young carers with a free choice:

1. "Embracing the challenge" - By accompanying their relatives, the children learn about various tasks to do with caregiving. Their interest grows and with time they take over responsibility and integrate the care needed for the sick member of the family into their own daily routine.

2. "Sharing the load" - Children see how the family needs to support the sick relative. Since they realize that the responsibility of caregiving has an emotional and physically negative effect on the healthy family members, they feel that it is their duty to take on caregiving tasks at home in order to relieve the others. 
Table 5: Characteristics of quantitative studies reporting correlations and associations

\begin{tabular}{|c|c|c|c|}
\hline N & Reference & Aim & Questionnaire; survey method \\
\hline 1. & $\begin{array}{l}\text { Pakenham } \\
\text { et al. (2007) } \\
\text { Australia }\end{array}$ & $\begin{array}{l}\text { Relations between social support, } \\
\text { appraisal and coping and both } \\
\text { positive and negative outcomes } \\
\text { in young carers }\end{array}$ & $\begin{array}{l}\text { Newly developed questionnaire, consisting of: } \\
\text { demographic information, caregiving context } \\
\text { variables, stress appraisal -, social support-, } \\
\text { coping strategies - and adjustment items }\end{array}$ \\
\hline 2. & $\begin{array}{l}\text { Ireland and } \\
\text { Pakenham } \\
(2010) \\
\text { Australia }\end{array}$ & $\begin{array}{l}\text { To develop an empirically derived } \\
\text { multi-item scale of care tasks } \\
\text { performed by young people in } \\
\text { the context of family illness/disability }\end{array}$ & $\begin{array}{l}\text { Based on the literature review and in } \\
\text { consultation with a reference group of five } \\
\text { young carers, a questionnaire was developed } \\
\text { (30 items): "Youth Activities of Caregiving } \\
\text { Scale (YACS)" }\end{array}$ \\
\hline
\end{tabular}

Study design, analysis, sample

3. Ireland and To (1) examine relations between Pakenham youth adjustment and three sets of (2010) predictors: parental illness/disability Australia characteristics, caregiving, and parent-child attachment, and (2) to explore differences on these variables between youths of parental physical illness/disability and youths of parental mental illness

4. Pakenham 1. to explore the dimensions of and Cox caregiving in children of a parent (2012) with MS

Australia $\quad 2$. to examine relations between the caregiving dimensions and child demographic, parental illness and caregiving context variables

3. to examine associations between the caregiving dimensions and child positive and negative adjustment outcomes, concurrently and over a 12-month interval 4. to examine levels of correspondence between parent and child ratings of the child's caregiving activities

5. Lloyd (2013)

Ireland
To look at the extent of caring responsibilities experienced by children and at the relationship between caring, educational experiences and academic performance, and children's happiness, health and well-being

6. Nagl-Cupal To describe the prevalence and et al. (2014) related factors of informal caregiving Austria performed by children To quantify caregiving activities and intensity, the motivation for To calculate the prevalence rate of all underage children in Austria based on the sample data

7. Cassidy To test whether a stress-coping model et al. (2014) can contribute to an explanation of the UK impact of caregiving and whether resilience and benefit finding can mediate that relationship
Newly developed questionnaire, consisting of: demographic information, illness and disability variables, Inventory of parent-child attachment (IPPA), the Young Carers of Parents Inventory (YCOPI), The Strengths and Difficulties Questionnaire (SDQ)

Two age-appropriate youth questionnaires: 10-13 years and 14-20 years were developed consisting of: demographic information, MS parent illness variables, caregiving context variables, Family responsibilities (YCOPI), Youth Activities of Caregiving Scale (YACS) and adjustment variables

Self-developed questionnaire, consisting of: sociodemographic data School data Health and wellbeing (Kidscreen)Happiness School and educational achievement (transfer-test, GL, AQE)

Self-developed questionnaire, consisting of: sociodemographic data, caregiving activities, type and frequency of illness of the family member in need, caregiving arrangement, motivations of caregiving, effects of caregiving, personal wishes

Self-developed questionnaire, consisting of: sociodemographic data, measures (Perceived social support Scale, Adolescent Coping Scale - short form, General Health Questionnaire, Brief Resilience Scale, 19 item index of help,
Survey

Bivariate and multivariate

analyses Convenience

sampling: Young carers

$n=100(\mathrm{~F} n=72 ; \mathrm{M} \mathrm{n}=28)$

Age: $10-25$

Care recipients: parents

\section{Survey}

Bivariate and multivariate

analyses Convenience

sampling: Young carers

$n=135(\mathrm{~F} n=81 ; \mathrm{M} n=54)$

Age: 10-24 Care recipients:

mother $n=73$, father $n=25$, sibling $n=37$

Survey

Bivariate and multivariate

analyses Convenience

sampling: Young carers $n=81$

( $\mathrm{F} n=53 ; \mathrm{M} n=28$ )

Age: $10-25$

Care recipients: mother

$n=56$, father $n=17$, both

parents $n=8$

Longitudinal study, Survey

Bivariate and multivariate

analyses Convenience sampling:

Assessed time T1:

Families $n=88$; parents $n=85$;

partners $n=55$; children

$(\mathrm{F} n=\mathrm{NR} ; \mathrm{M} n=\mathrm{NR}) n=130$

Assessed time T2 (after 12 month):

$n=$ NR Families; $n=71$ parents;

$n=48$ partners; $n=91$ children

( $F n=N R ; M n=N R$ ) Age: $10-20$

Care recipients: parents

Kids'Life and Times Survey (online) Univariate and bivariate analysis Random sample: $n=4029$ children Age: 10-11

Care recipient: grandmother $44 \%$, mother 33\%, brother 33\%, grandfather $27 \%$, father $26 \%$, sister $26 \%$

Descriptive cross-sectional study

Univariate, bivariate and multivariate analysis

Random sample (multi-level

probability sample): $n=7403$

children ( $F n=53,5 \%$; $M n=46,5 \%$ )

Age: 10-14

Care recipient: mother 23\%, grandmother $22 \%$, father $14 \%$, grandfather $11 \%$, siblings $12 \%$

Survey

univariate, bivariate and multivariate analysis

Convenience sample: $n=442$

children ( $F n=268 ; M n=174)$ 
Table 5: Characteristics of quantitative studies reporting correlations and associations (Continued)

\begin{tabular}{|c|c|c|c|}
\hline N Reference & Aim & Questionnaire; survey method & Study design, analysis, sample \\
\hline & & $\begin{array}{l}\text { The Perceived Impact of Child Care-giving } \\
\text { Scale, The Benefit Finding in Child } \\
\text { Caregivers Scale) }\end{array}$ & $\begin{array}{l}\text { Age: } 12-16 \\
\text { Care recipient: } 203 \text { children care for } \\
\text { parents, } 168 \text { children care for a sibling, } \\
71 \text { care for more than one family member }\end{array}$ \\
\hline $\begin{array}{l}\text { 8. Pakenham } \\
\text { 9. and Cox } \\
\text { (2015) } \\
\text { Australia } \\
\text { Van Loon } \\
\text { et al.(2017) } \\
\text { Netherlands }\end{array}$ & $\begin{array}{l}\text { To examine differences in two } \\
\text { proposed psychological components of } \\
\text { role redistribution between youth of a } \\
\text { parent with illness and their peers from } \\
\text { 'healthy' families } \\
\text { To examine the effect of parentification } \\
\text { on both internalizing and externalizing } \\
\text { problems of Adolescents who have a } \\
\text { Parent with Mental Health Problems }\end{array}$ & $\begin{array}{l}\text { Self-developed questionnaire, consisting of: } \\
\text { Family health status, illness category, relative } \\
\text { disadvantage, remoteness, national origins, } \\
\text { caregiving responsibilities and experiences } \\
\text { (Young Carer of Parents Inventory-Part A) } \\
\text { The Parentification Questionnaire-Youth } \\
\text { (PQ-Y), consists of } 20 \text { items measuring the } \\
\text { caregiving behaviors of youth in their family; } \\
\text { The Youth Self-Report (YSR) measuring the } \\
\text { problems adolescents experienced in the } \\
\text { previous } 6 \text { months. } \\
\text { The Perceived Stress Scale (PSS-4) - } \\
\text { consisting of four items measuring the } \\
\text { degree to which adolescents perceived } \\
\text { their lives as uncontrollable, unpredictable, } \\
\text { or overloaded in the past month; }\end{array}$ & $\begin{array}{l}\text { Survey } \\
\text { Bivariate and multivariate analysis } \\
\text { Random. sample: children } n=2474 \\
\text { (F } n=N R ; M n=N R) \\
\text { Age: } 9-20 \\
\text { Care recipient: parents and other ill family } \\
\text { member, several ill family member Survey } \\
\text { Bivariate and multivariate analyses } \\
\text { Convenience sample: } n=118 \text { adolescents } \\
\text { (F } n=50,8 \% ; M n=49,2 \%) \\
\text { Age: } 11-16 \\
\text { Care recipient: parents with a mental } \\
\text { illness: mother } 70,3 \% \text {, father } 29,7 \%\end{array}$ \\
\hline
\end{tabular}

Table 6: Methodological quality of quantitative studies reporting correlations and associations

\begin{tabular}{|c|c|c|c|c|c|c|c|c|c|}
\hline 1. Population & 1. & 2. & 3. & 4. & 5. & 6. & 7. & 8. & 9 \\
\hline 1.1 Is the source population or source area well described? & + & ++ & - & - & ++ & ++ & ++ & ++ & ++ \\
\hline 1.2 Is the eligible population or area representative of the source population or area? & ++ & ++ & ++ & + & ++ & ++ & + & + & ++ \\
\hline 1.3 Do the selected participants or areas represent the eligible population or area? & - & - & + & + & + & + & + & + & ++ \\
\hline \multicolumn{10}{|l|}{ 2. Method of selection of exposure (or comparison) group } \\
\hline 2.1 Selection of exposure (and comparison) group. How was selection bias minimised? & NR & - & NR & - & - & - & - & - & ++ \\
\hline 2.2 Was the selection of explanatory variables based on a sound theoretical basis? & ++ & ++ & ++ & ++ & + & ++ & ++ & ++ & ++ \\
\hline 2.3 Was the contamination acceptably low? & NA & NA & NA & NA & NA & NA & NA & NA & ++ \\
\hline 2.4 How well were likely confounding factors identified and controlled? & $N R$ & - & NR & - & - & - & - & - & + \\
\hline 2.5 Is the setting applicable to the UK? (for this review: Germany) & + & + & + & + & + & + & + & + & + \\
\hline \multicolumn{10}{|l|}{ 3. Outcomes } \\
\hline 3.1 Were the outcome measures and procedures reliable? & ++ & ++ & ++ & ++ & ++ & ++ & ++ & ++ & + \\
\hline 3.2 Were the outcome measurements complete? & ++ & ++ & ++ & ++ & ++ & ++ & ++ & ++ & + \\
\hline 3.3 Were all the important outcomes assessed? & ++ & ++ & ++ & ++ & ++ & ++ & ++ & ++ & + \\
\hline 3.4 Was there a similar follow-up time in exposure and comparison groups? & NA & NA & NA & + & NA & NA & NA & NA & + \\
\hline 3.5 Was follow-up time meaningful? & NA & NA & NA & ++ & NA & NA & NA & NA & + \\
\hline \multicolumn{10}{|l|}{ 4. Analysis } \\
\hline 4.1 Was the study sufficiently powered to detect an intervention effect (if one exists)? & NA & NA & NA & NA & NA & NA & NA & NA & ++ \\
\hline 4.2 Were multiple explanatory variables considered in the analyses? & ++ & ++ & ++ & ++ & ++ & ++ & ++ & ++ & ++ \\
\hline 4.3 Were the analytical methods appropriate? & ++ & ++ & ++ & ++ & ++ & ++ & ++ & ++ & ++ \\
\hline 4.6 Was the precision of association given or calculable? Is association meaningful? & ++ & ++ & ++ & ++ & ++ & ++ & ++ & ++ & ++ \\
\hline \multicolumn{10}{|l|}{ 5. Summary } \\
\hline 5.1 Are the study results internally valid (i.e. unbiased)? & ++ & ++ & ++ & ++ & + & ++ & ++ & ++ & ++ \\
\hline 5.2 Are the findings generalisable to the source population (i.e. externally valid)? & + & ++ & + & ++ & + & + & + & + & ++ \\
\hline
\end{tabular}




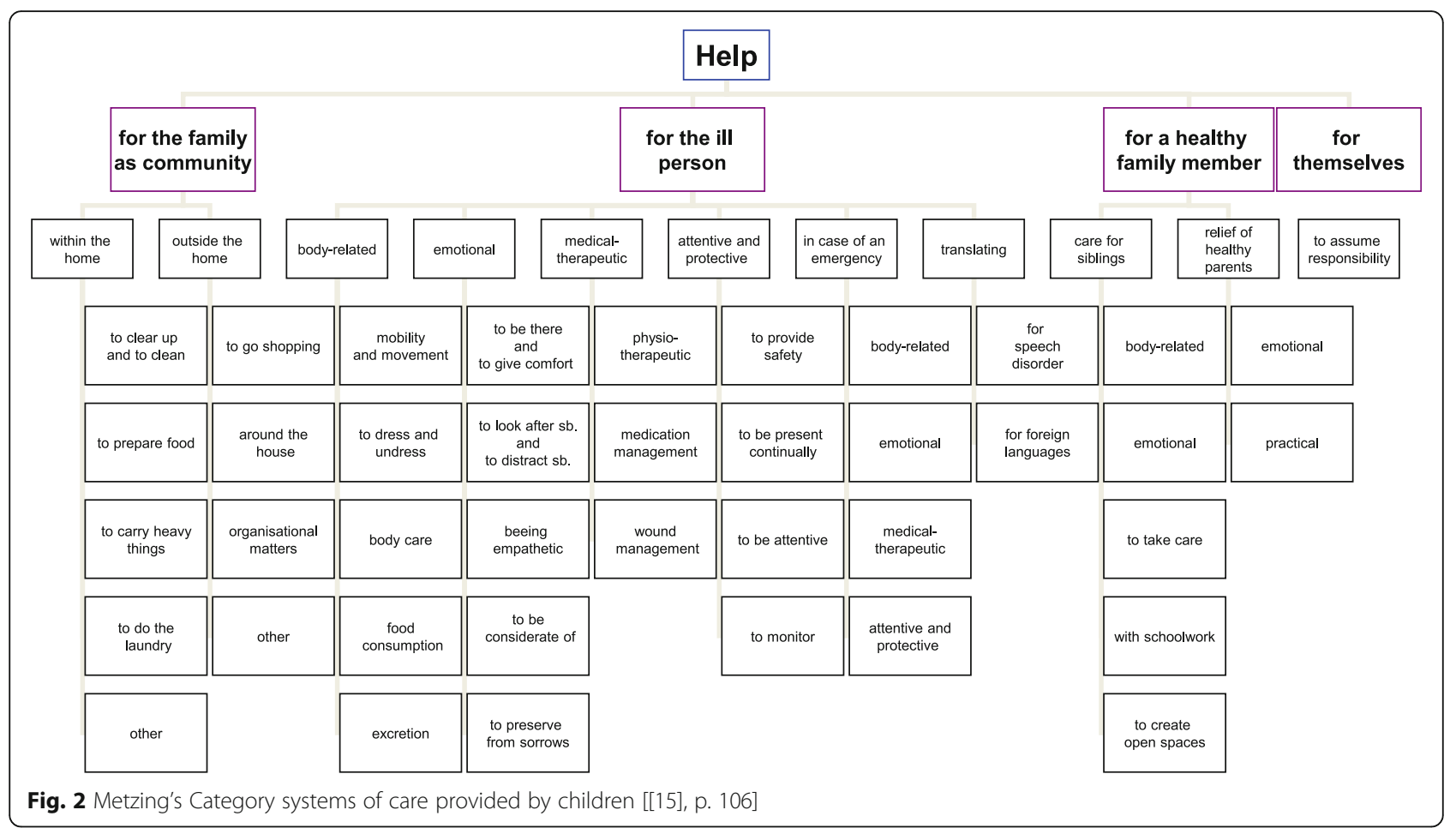

3. "Being assigned" - In this case the caring role is assigned to the children by other family members. These children do not fulfill their caregiving tasks for their own sake or interest but because the work has to be done.

It depends on the resources (for instance, the number of shoulders available in the family) as to how much responsibility the family can assume.

\section{Impact of caring on the children}

Analogous to the previous review, the results in this section show that taking on various caregiving tasks in the family can have a positive [28] and also negative impact on their development $[19,23,25,32]$ as will be described in what follows.

\section{Impact on family life}

A chronic illness brings different changes in a family, which can be seen, for instance, in the surrounding circumstances: coexisting in everyday life, social interactions and utilizing leisure time $[25,28]$.

Children begin to watch their sick parents closely, noting exactly the good days and the bad ones. Worry is omnipresent in their daily lives [28]. They stay in the vicinity of the relative, spend most of their time at home and are prepared to carry out everything necessary to keep the family's daily routine up and running $[20,23]$. So these children bearing the responsibility of being caregivers have a different kind of relationship with their relatives than their peers who do not have an ill person within their family circle [30]. The illness and the changes in circumstances lead to a stronger emotional bond between the members of a family [20]. They have a strong "we-feeling" in the family, are satisfied with the family's team spirit and are able to confront all the demands of everyday life [13]. Furthermore, a parent-child relationship is stronger if a parent has a physical impairment than if the disease is a psychological one [12]. Affected families frequently experience tensions and potential conflict [32], reaching from domestic violence via detachment from the family to considerable shifts in a family's formation [29]. If one parent suffers from a mental illness and is thus unable to handle the demands of the family, it is usually the other healthy parent who becomes the head of the family and keeps everything running [14]. The children and adolescents do not only identify this shift in the parental structure but, above all, they acknowledge it; some of them develop a particularly close relationship, not to say a partnership, with the healthy parent. It is therefore not surprising that these children and adolescents want to protect the healthy parent and do not verbalize their own needs and worries [26, 32]. According to their relationship towards the mentally ill parent, they even suppress their own needs as they recognize the changes in the personality and behavior of the parent. Thus the communication from the children's perspective becomes one-sided, and the 
relationship is increasingly characterized by compassion $[26,32]$. In the Grounded Theory study by Mauseth \& Hjalmhult [28], which examines the experiences of adolescents with a parent suffering from MS, it was found that the children's successful internal conflict with the family's situation depends greatly on the openness with which the parents confront their own illness, on the communication within the family and on the information about the illness itself.

Ortner [14] points out that the situation influences the family in various ways, depending on whether the mother or the father has become ill. If the mother, who has a familial "key function", falls out due to illness, this affects the family's daily routine within a very short time. On the other hand, if the father becomes ill, the effect on the family structure is of a long-term financial nature.

Many families suffer from financial restrictions due to an illness [13, 25], which also makes the acceptance of support more difficult. This is why the children prefer to take over caring roles [23]. The children are usually aware of the financial problems and do not have the courage to speak to their parents about money required for leisure activities or school trips [22].

\section{Psychosocial impact}

The emotional and social impact of young carers is welldescribed in the recent literature and comparable with the findings of the previous literature study. The psychosocial impact is not only influenced by the curvilinear course of the chronic illness and but depends also on the children's involvement in caregiving [25].

\section{Emotional impact}

Children and adolescents as informal carers are frequently confronted with manifold emotions and feelings [33]. The negative emotions range from anxiety and guilt up to embarrassment through the affected family member. Fear both for $[15,27]$ and of the parents are typical for these children. They suffer when the parents are in pain or react with extreme anxiety if acute danger to life occurs. The children are afraid of their mentally ill parents when an acute psychological crisis takes place [13]. Such fears are constant, since the course of the illness and the care needed can hardly be predicted.

According to Ortner [14], a distinctive feature of families with a mentally ill member is that young carers are often confronted with feelings of guilt. Accordingly, they feel guilty and consequently remain mentally concerned about the family once they go their own way. Young carers feel guilty if they lose patience with their ill parent $[13,26]$, if they think that they cannot provide sufficient help for their ill parent [28] or if they perceive that other people are prepared to take on more tasks [29]. Again, others who grow up with a mentally ill parent are confronted with the accusation of not looking after him/her enough, which they then experience as upsetting [14]. Some children describe their experiences with caregiving as being unfair and unsuitable owing to age and developmental factors. They feel threatened and more overwhelmed than challenged [31]. It should in fact be noted that these experiences and the resulting stress are induced by "internalizing, such as depression, and externalizing behavior, such as aggression" of these children [33].

Feelings of shame or embarrassment are often felt by young carers [33] and their sick family members, which are usually in connection with intimate care, where such situations are difficult for both sides. For the children, it represents a big hurdle if, for instance, the father has to be accompanied to the toilet or the mother needs help with bathing $[13,17]$. There are also some reports that, in certain situations, children feel ashamed of their physically impaired parent or of the assistive devices they use. They notice this particularly when they accompany their parents outside the home [13, 27]. This feeling of shame develops from the fear of being stigmatized [20].

Apart from these negative effects, other authors confirm that young carers reach an early maturity $[5,13,15,26]$ and greater independency [15].

\section{Social impact}

Children have to manage "changing complexities" and have to set priorities throughout their own social life [25 P.31]. Many of the children who participated in the study by Metzing [13] had numerous hobbies and fostered friendly relationships and only seldom they have to cancel a social activity due to their responsibilities at home, which they perceived as normalcy. For them, their home commitments are part of their life and are not felt to be a restriction.

In contrast, others have very little time for themselves, could hardly take part in social life and have only very limited friendly relationships - in some cases they were even socially isolated.

\section{Impact on school life}

Some young carers are victims of bullying and harassment at school $[18,21,26,29]$ and experience stigmatization [14] due to the diseases and psychological disorders of their ill family members. For some children, school is the place where they can forget about home, spend time with friends and be content about the free time gained [22].

In the study by Lloyd [21, P.76], a third of the identified ten- and eleven-year-old carers reported having been victims of physical violence at school $\left(X^{2}=101.20\right.$, $d f=2, p<0.001 ;$ Cramer's $V=0.17$ ) and nearly half of 
them were bullied in other ways $\left(X^{2}=765.69, d f=2\right.$, $p<0.001$; Cramer's $V=0.15)$. Conflicts outside the family are due particularly to the societal lack of awareness and knowledge about disease-specific personality changes. In addition, the fact that some children are scaled down to their parents' illness and that the efforts they muster at home are not honored is a dramatic experience [22]. Their school friends are condescending towards them $[18,30]$. From the perspective of the children concerned, not only their friends but also their teachers lack awareness and respect for their particular circumstances [22]. If these children are irritable when they come to school, or are discontented or get worked up about little things, then conflicts with their school friends can build up. They are unable to understand their own behaviour and get a bad conscience regarding their school friends, which increases the burden even more [34]. Young carers are isolated from their school friends; they are reserved and feel like outsiders [17, 25]. This exclusion also means that they have little contact with other children in similar circumstances [22].

According to several studies, some young carers find it difficult to master their everyday life at school $[5,13,15$, $18,21,25]$. These children do not manage to combine their role in the family with the demands placed on them at school. Some children suffer from not making good progress in school due to their lack of concentration, and also worry about not getting good results which would mean they could not afford to study or support their parents financially in the future [13]. The results from Lloyd's survey [21] indicate the danger of lower educational expectations for young carers. According to some children, difficulties at school are due to the lack of parental support in learning at home; they miss the care and control of the parents with regard to homework [25]. Other reasons are: lack of time [5], distance to school, lack of understanding in their social surroundings [34]. In some studies, the focus is on school absences $[13,15,25]$.

\section{Physical impact}

Comparable with the previous review, the studies contain only a few statements concerning the physical effects that living with a chronically ill family member can bring with it.

Lloyd [21] compares the health of ten- and elevenyear-old schoolchildren living in families without an ill person with the health of young carers of the same age. Although she comes to the conclusion that young carers estimate their health situation as less than excellent or very good in comparison with those of the same age and although this difference is statistically significant $\left(X^{2}=14.12, d f=4, p<0.01\right)$, the author points out that the correlation is weak (Cramer's $V=0.061$ ). Moreover,
Nagl-Cupal et al. [5] also determine statistically significant adverse physical health effects for the group of young carers in their population of ten- to 14-year-olds. By identifying manifest symptoms such as sleeping disorders, tiredness, headaches and backache as physical effects, they confirm the results contained in the literature review by Metzing and Schnepp [3].

\section{Needs}

The studies describe a wide spectrum of young carers' personal needs; however, the main wish is that the family may "continue to live as normally as possible" [13, P.127]. The children of course want the sick person to recover but it is not the disease that is in the foreground, it is the family as a whole [28]. If children were to receive the support needed to maintain the family's daily routine, it would be a considerable relief not only for the family but also for the children themselves [13].

\section{Maintaining the familial everyday life}

Children involved in caring for a family member require professional, flexible support that is oriented to their actual life [13]. Affected children highlight particularly the necessity of having needs-oriented support that values the cohesion and intimacy of the family [32]. The study by Moore and McArthur [22] shows that families receive support with, for example, changing dressings, bathing, preparing medication, mobilization and transport. In addition, young carers emphasize that it would reinforce their own feeling of safety if these caregiving activities were supplemented by flexible, personal and emotional backing and monitoring by the relatives, especially if they are not located in the immediate vicinity of their home. From the children's perspective this would greatly help to reduce stress in the family, avoid conflicts and strengthen the family's solidarity [13, 20, 27].

These families are dominated by the fear of separation and tearing apart. As reported by Moore and McArthur [22], many of the study participants would very much like to get external support; however, the family is afraid that their situation would be criticized, the children removed and the whole family loyalty destroyed if offers of support were accepted [13].

It is important for children to receive practical and for their age appropriate help as well as counseling about the illness $[13,20,27,28]$. They express the wish to have detailed information about existing counseling possibilities in order to get access to specific practical advice in connection with the disease [34].

Another important point is financial support for affected families so that they are not socially excluded and the children are able to participate. A chronic illness often leads young parents into disablement and occupational incapacity $[13,27,34]$. 


\section{Attention, affection, mutual exchange}

For young carers it is essential to receive recognition for the responsibilities they have taken on and also to experience support in their tasks [27, 29, 31]. Equally essential are familial appreciation and social perception $[28,33]$. The children look for and find confirmation outside the family, in school, in their leisure time or in support groups [29, 31]. The importance of such programs lies in their main concept, which is to impart the recognition needed and to enable the young carers to feel appreciated [31].

Ortner [14] and Van Loon et al. [33] underline that intensive talks and closeness to the sick parent are particularly valuable for children of mentally ill parents because the child's need for attention and affection can thus be satisfied. In cases where this does not seem possible and where the healthy parent is barely able to take over a protective function, the children long for someone to talk to about their situation. This person can be a more distant relation who is then expected to initiate the help required.

A special form of closeness and affection is frequently expected from contact to people in similar situations $[18,23,27,32]$. In the children's opinion, the schools could play an important role in identifying such contacts and helping to form networks [34].

In the living environments "school" and "circle of friends" the children look to their teachers and friends for a sympathetic approach, which could contribute to them feeling completely accepted and understood. On the one hand, they would like to talk about their own lives but on the other hand, they do not want to be forced to tell their whole life story [25].

The children also expressed the wish to be protected from bullying at school. In their opinion schools could do more to prevent bullying if the teachers were to change their approach to disabilities and diseases, taking a clear stance and trying to give the pupils a change in perspective. If this were to result in young carers losing their feeling of being in an exceptional position and of being different, then identification as a young carer could have a positive impact on their lives [34].

\section{Having time and space for themselves}

In order to achieve a temporary relief from difficult family situations, it is essential that the children and adolescents of mentally ill relatives find space and time for themselves [29]. Ortner [14, P. 196] calls this "being able to breathe" in order to "find some peace". These recuperative phases strengthen them for the time with the family $[29,34]$. In moments like that they want to have no responsibilities, do not want to think or worry about the familial situation, just want a good time and relax. They want to escape from the situation, build up social relationships outside the family [28]; freed from the responsibilities of caregiving, they want to search for their own identity and make plans for the future. Fulfilling these needs presents a way with which they can ensure sustainably both their own well-being and that of the family [29].

The wish for recreation and time off is underlined also by the children of physically ill parents, especially at times when they themselves are ill or when good performances are demanded of them at school or when a conflict situation arises in the family. Affected children want to be "simply just" a child [13]. They need time for friends and hobbies and to build up their own lives $[13,27,28]$.

\section{Coping actions}

Children and adolescents in families with a chronically ill member take it for granted that they have to deal with the complex demands of everyday life on their own [13, 22, 28]. To cope with these demands, young carers try to find and maintain the balance between private and familial life [27]. To do this they use various coping strategies and "problem-focused and emotionfocused behavioral strategies" [28, P.859] .

"Helping others" is one of the most important active coping strategies $[13,17,25,30]$ and helps to reduce their own feelings of guilt and anxiety [30]. Many young carers refer to their daily tasks as their "job" which gives their role as caregiver a positive meaning, strengthening their feeling of pride, "being normal" and self-esteem $[17,27]$. Since they are at all times prepared to help the ill member of the family, they are less worried and can manage the situations at home. At the same time, these children recognize their own competences and develop positive feelings of self-esteem $[13,17,30]$.

In many families all the members try to distribute the tasks evenly among the resources available to them, i.e. shoulder them jointly [14]. If that succeeds, these children develop a very strong "we-feeling" in the family, are satisfied with the family's team spirit and are able to confront all the demands of everyday life [13].

Another of the children's coping strategies is to behave considerately towards their own family members $[25,30]$. The children's own needs are pushed aside and those of the family are accepted $[22,25,28,30]$. There the children rarely mention being overwhelmed; they hold their own feelings back in order not to endanger the relationship to the family or to avoid an escalation that they might later regret [27, 34].

Putting the focus outside the family itself is another coping strategy [28]. Children of mentally ill parents particularly like to channel their energy outside family life, e.g. in hobbies [29]. They protect themselves by putting some distance - both spatially and emotionally - between 
themselves and the family [14, 27]. By moving into their own accommodation, some adolescents actively create a distance to the particularly complex situation of growing up with a mentally ill family member [14].

To have time for themselves is the strategy children apply in order to distract themselves from the home situation and to relax $[27,28]$.

A further meaningful form of coping is to talk about everything - whether in the family or outside [13, 18, 27, 28 ]. The young carers mostly talk to siblings, friends and people who have had similar experiences $[15,18,26,29]$ and only with a selected circle of friends from whom they can expect support [32]. Because these people are "simply there", they are an important source of listeners for handling problems, reacting empathically to a particular situation $[26,32]$.

Withdrawal is the reaction of young carers if they feel themselves misunderstood or ignored by society, and is a frequently used strategy [27]. In order to protect themselves and their family, young carers sometimes ignore this type of behaviour [26], drawing back and saying nothing about their own life $[13,17]$. In contrast, other children growing up with a parent who has dementia have found it beneficial to be open and to talk about the disease with other people [26].

\section{Discussion}

The objective of this review was to expand on a previous literature review $[2,3]$ and to bundle anew the internationally evolved knowledge about children and adolescents as informal carers.

In comparison to the previous review where the situation of young carers was mostly the subject of research in Great Britain, the United States and Australia [2, 3], further studies from those countries and first results from German-language countries and Norway have become available in the meantime $[5,13,14,27]$. Based on the included studies, it has been possible to confirm and consolidate the previous knowledge about the characteristic attributes of children and families concerned. In addition, studies could be included that focus i.e. on how these familial caregiving arrangements originated [e.g. 5, 13, 15, 25] and also reviews concerning the children's coping management [e.g. 14, 17, 26, 30]. It has furthermore been possible to identify theoretical models that help to describe and explain the phenomenon of "young carers" [13, 25]. However, further research is required since aspects such as gender or migration have up to now either been disregarded or hardly noted. The results of the current review are discussed in the following.

To date, internationally significant figures on the prevalence of young carers are lacking. The reasons are to be found in the methodical challenges, since due to the expected low prevalence a large sample is required in order to be able to identify the target group at all. It is also extremely difficult to gain access to the target group $[5,23,27,35]$. During the whole research period only one survey from Austria was identified [5], the results of which could be roughly compared with the previous parameters from Great Britain [4, 36]. Another German-language survey is currently in the data analysis phase.

Characteristic attributes of young carers are similar to each other but these are shown in different ways in the studies. Empirically based systems of categories showing young carers' activities are indeed available [e.g. 5, 13, 19] but internationally are not applied homogeneously so that only a limited comparison of study results from different research groups is possible. A further difficulty for comparing results lies in the varying age definitions for young carers in other countries [2], particularly in Australia where young adults up to 25 years of age are included in the surveys [12, 16, 19, 22, 24, 34, 37].

Both qualitative and quantitative study results show a higher proportion of girls as young carers. Up to now, the theoretical explanation for this phenomenon has hardly been the subject of research interest and genderspecific studies on young carers are one of the largely unexplored fields so far. Considering the fact that family caregiving these days is usually a woman's affair [38], the authors find that it is important not to lose sight of this gender-specific difference in order to prevent girls taking up "early caregiving careers" [5].

Several studies have focused on the motives for taking on caregiving tasks as well as on the influencing factors and on various reasons for the development of these familial caregiving arrangements [5, 13, 25]. This knowledge can help the support system to recognize the interaction between favorable risk and influencing factors in order to react in time to stress in the family and to meeting their needs. This could prevent the children suffering from disadvantageous effects and overwhelming later in life. It is indeed difficult to identify the point in time when a child takes on a caregiving role, since the increasing help and support needed is described in most cases as a slow, drawn-out process [13, 25, 32]. Nevertheless, the literature shows that there are specific diseases, such as multiple sclerosis or dementia [24, 26, 32], where certain points of time during the course of the disease should be given more attention, e.g. at diagnosis or when a new flare or attack occurs.

Current study results confirm both positive and negative influences on the development of caregiving children and adolescents as a consequence of the amount of caregiving involved [5, 13, 19, 23, 25, 32]. If, because of their caregiving role, young carers are unable to participate in activities suitable for their age and 
sphere, this has an adverse impact on their lives and social isolation becomes a threat. Emotional effects such as worry, sadness and anxiety or shame and fear of stigmatization are additional aspects about which they do not like to speak and which lead to the young carers withdrawing from their social networks, making life even more difficult for them. To prevent this happening, it is necessary to build up social awareness and eliminate taboos about this theme; the support system must show empathy and be attentive so that warning signs can be recognized in time and appropriate actions taken. At the same time research for retrospective surveys is necessary to get a better understanding for the impact on later life and to develop adequate prevention methods.

The physical effects of the caregiving role of affected children are rarely the subject of discussion in current studies. Only McDonald et al. [15] and NaglCupal et al. [5] point in their studies to the implications for young carers' health, which is a surprising result considering the manifold and physically strenuous support some children and adolescents provide. A possible reason for this may lie in the nature of the study designs here. With one exception, the studies are concerned with one-off cross-sectional surveys with mostly quite young participants. Physical effects such as chronic headaches or exhaustion and particularly long-term consequences like backache, postural deformities or addiction cannot be portrayed in the existing studies. Here, too, longitudinal studies and retrospective surveys are called for.

Some of the children concerned manage to develop strategies to counteract their own situation. Findings relating to their coping management are a new theme identified in international literature $[13,16,17,25$, $27,29,30,32]$, in particular the search for and building up of new relationships with similarly affected children and adolescents. Such relationships of trust enable young carers to talk about their own circumstances, to feel understood, to be outside their own home and able to speak freely. Other strategies are to create space outside the family or to deliberately commit themselves to helping other people in order to experience a feeling of esteem. Some of the young carers inform themselves about the disease in question and the support available, or are either consciously open about the situation or avoid confrontation by withdrawing. Coping management also involves connoting the support positively in order to reduce their own burden.

For young carers to succeed in dealing well with their specific situation, needs-based and service-oriented support is required. A family-oriented perspective is vital as well, looking at the family as a whole $[39,40]$.
From the findings of this literature review, the following concrete practical recommendations for supporting young carers can be derived:

- Cooperation with the German Child Welfare Association to initiate regular workshops in schools on the subject "young carers" in order to develop empathy among teachers and peers and to prevent the stigmatization of young carers.

- Health professionals should be sensitized towards the specific situation of these families/children, thus developing their empathy towards those concerned. The target should not be just to find access to the families but also to create a trusting relationship to them in order to develop individual solutions for each family and to put these into practice by working closely with the families.

- It is imperative that physicians, carers, child and family psychologists should take care that the balance between the familial life of the children and their social life is sustained. The findings in this review may be able to help the support system to identify and classify the extent and type of help given by children. "Gaps" in the family resulting from the illness may be recognized and the specific needs estimated of both the young carers and their ill relative. A true and individual picture of each family can be achieved if influencing and risk factors are perceived (e.g. family constellations, financial, familial and social resources etc.) [41]. Providing relief for the families can contribute to the children having more time and space for their own needs [42], thus resulting in a framework for coping.

This literature review may have several limitations. a) Only publications from peer-reviewed journals and qualified articles known to the authors were taken into consideration. This means that good quality studies that had been published by the authors themselves or as monographs were not identified. b) The "interpretability" can be influenced when analyzing large studies with varying study designs and measuring instruments. To deal with this problem, data analysis was carried out thematically. The identified topics were structured thematically in concepts to facilitate interpretation of the results per outcome category. c) A further possible limitation may be the heterogeneity of the young carers'ages. However, the authors were unable to have any effect on this problem because it is not mentioned explicitly in the studies.

\section{Conclusion}

The subject "young carers" has received increased attention in the international scientific community over the last ten years. The studies included in this review 
answer questions concerning ways of life, needs and requirements as well as the coping management of young carers. Future research should be directed towards specific disease patterns, towards the integration of children from families with dependence syndromes and also take aspects such as gender and migration into consideration. Furthermore, there is still a need for retrospective studies and long-term observations.

\section{Acknowledgments}

The manuscript has been revised and partly translated by a native speaker.

\section{Funding}

The study was funded by the German Federal Ministry of Health.

\section{Availability of data and materials}

The datasets supporting the conclusions of this manuscript are included in Tables 123456 within the paper.

\section{Authors' contributions}

We hereby state that all authors meet the criteria for authorship, have approved the final article and that all entitled to authorship are listed as authors.

\section{Ethics approval and consent to participate}

Not required.

\section{Consent for publication}

Not applicable.

\section{Competing interests}

We, the authors of this manuscript, declare that we have no competing interests.

\section{Publisher's Note}

Springer Nature remains neutral with regard to jurisdictional claims in published maps and institutional affiliations.

Received: 9 May 2017 Accepted: 20 October 2017

Published online: 10 November 2017

\section{References}

1. Becker S. Young Carers. In: Davies M, editor. The Blackwell Encyclopedia of Social Work. Oxford: Edn. Edited by: Oxford Blackwell Publishers Ltd 378; 2000. p. 432.

2. Metzing S, Schnepp W. Children and adolescents as caregivers: who they are and what they do. An international literature review (1990-2006) [German]. Pflege. 2007;20(6):323-30.

3. Metzing S, Schnepp W. The impact of caring on young carer's [sic] lives. An international literature review (1990-2006) [German]. Pflege. 2007;20(6):331-6.

4. Census 2011 [https://www.ons.gov.uk/census/2011census].

5. Nagl-Cupal M, Daniel M, Koller MM, Mayer H. Prevalence and effects of caregiving on children. J Adv Nurs. 2014;70(10):2314-25.

6. Becker S: Young Carers international: reflections on 25 years of research, campaigning \& life. In., 29.05.2017 edn. Malmo, Sweden: the Swedish family care competence Centre, SFCCC - Nationellt kompetenscentrum anhöriga. 2nd international conference "every child has the right to..." 2017.

7. Norman I, Griffiths P. The rise and rise of the systematic review. Int I Nurs Stud. 2014;51(1):1-3.

8. Higgins J, Green S: Cochrane Handbook for Systematic Reviews of Interventions Version 5.1.0 [updated March 2011]. In.: The Cochrane Collaboration, 2011.; 2011.

9. Carers Australia [http://carersaustralia.com.au/about-carers/young-carers2/].

10. Critical Appraisal Skills Programme (2017). CASP (systematic review checklist and qualitative research checklist). [online] available at: [http://www.casp-uk. net/checklists].

11. Methods for the development of NICE public health guidance (third edition) [https://www.nice.org.uk/process/pmg4/chapter/introduction].
12. Ireland MJ, Pakenham Kl. Youth adjustment to parental illness or disability: the role of illness characteristics, caregiving, and attachment. Psychol Health Med. 2010;15(6):632-45.

13. Metzing S. Kinder und Jugendliche als pflegende Angehörige. Erleben und Gestalten familialer Pflege, vol. vol. 1. Bern: Verlag Hans Huber; 2007.

14. Ortner K. Zwischen den Polen pendeln - Leben mit einem psychisch kranken Elternteil. In: Metzin S, Wien N-CM, editors. Facultas Familienorientierte Pflegeforschung Kinder und Jugendliche im Brennpunkt, vol. Volume 1; 2014. p. 185-208.

15. McDonald J, Cumming J, Dew K: An exploratory study of young carers and their families in New Zealand. In., vol. 4. New Zealand: New Zealand journal of social sciences online; 2009: 115-129.

16. Pakenham Kl, Chiu J, Bursnall S, Cannon T. Relations between social support, appraisal and coping and both positive and negative outcomes in young carers. J Health Psychol. 2007;12(1):89-102.

17. Bolas H, Van Wersch A, Flynn D. The well-being of young people who care for a dependent relative: an interpretative phenomenological analysis. Psychol Health. 2007;22(7):829-50.

18. Richardson K, Jinks A, Roberts B. Qualitative evaluation of a young carers' initiative. J Child Health Care. 2009;13(2):150-60.

19. Ireland MJ, Pakenham Kl. The nature of youth care tasks in families experiencing chronic illness/disability: development of the youth activities of caregiving scale (YACS). Psychol Health. 2010;25(6):713-31.

20. Marote ASF, Pinto CA, da Rocha Vieira M. Barbiéri-Figueiredo MdCA, Nunes Pedrosa PM: children as carers: an integrative review. Revista LatinoAmericana de Enfermagem (RLAE). 2012;20(6):1196-205.1110p

21. Lloyd K. Happiness and well-being of young Carers: extent, nature and correlates of caring among 10 and 11 year old school children. J Happiness Stud. 2013;14(1):67-80.

22. Moore T, McArthur M. We're all in it together: supporting young carers and their families in Australia. Health Soc Care Community. 2007;15(6):561-8.

23. Metzing-Blau S, Schnepp W. Young carers in Germany: to live on as normal as possible - a grounded theory study. BMC Nurs. 2008;7:15.

24. Pakenham Kl, Cox S. The nature of caregiving in children of a parent with multiple sclerosis from multiple sources and the associations between caregiving activities and youth adjustment overtime. Psychol Health. 2012; 27(3):324-46.

25. Kain CA. Muddling through: how young caregivers manage changing complexities. Boca Raton: Florida Atlantic University; 2009. https://pqdtopen. proquest.com/doc/304924446.html?FMT=Al.

26. Nichols KR, Fam D, Cook C, Pearce M, Elliot G, Baago S, Rockwood K, Chow TW. When dementia is in the house: needs assessment survey for young caregivers. Can J Neurol Sci. 2013;40(1):21-8.

27. Großmann N. Young Carers - Kinder kranker Eltern, Bedarfserhebung, Entwicklung, Umsetzung und Evaluation eines Präventionsangebotes. Germany: Europa-Universität Flensburg; 2015.

28. Mauseth T, Hjalmhult E. Adolescents' experiences on coping with parental multiple sclerosis: a grounded theory study. J Clin Nurs. 2016; 25(5-6):856-65.

29. Doutre G, Rob G, Anne K-E. Listening to the voices of young carers using interpretative phenomenological analysis and a strengths-based perspective. Educational \& Child Psychology. 2013;30(4):30-43.

30. Earley L, Cushway D, Cassidy T. Children's perceptions and experiences of care giving: a focus group study. Couns Psychol Q. 2007;20(1):69-80.

31. Cassidy TMM. Benefit finding and resilience in child caregivers. Br J Health Psychol. 2014;19(3):606-18.

32. Svanberg E, Stott J, Spector A. Just helping': children living with a parent with young onset dementia. Aging Ment Health. 2010;14(6):740-51.

33. Van Loon LMA, Van de Ven, M. O. M., van Doesum, K. T. M., Hosman, C. M. H. And Witteman, C. L. M. : Parentification, stress, and problem behavior of adolescents who have a parent with mental health problems. Fam. Proc., 56: 141-153. doi:https://doi.org/10.1111/famp.12165. Fam Process 2017, 56(1):141-153.

34. Moore T, McArthur M, Morrow R. Attendance, achievement and participation: young Carers' experiences of School in Australia. Aust J Educ. 2009;53:5-18.

35. Hurst SA. Vulnerability in research and health care; describing the elephant in the room? Bioethics. 2008;22(4):191-202.

36. Census 2001 [https://www.ons.gov.uk/census/2001censusandearlier].

37. Pakenham Kl, Cox S. The effects of parental illness and other ill family members on youth caregiving experiences. Psychol Health. 2015;30(7):857-78. 
38. Gender in der Pflege, Herausforderungen für die Politik [http://ibrary.fes.de/ pdf-files/wiso/05587.pdf].

39. Frank J, Slatcher C. Supporting young carers and their families using a whole family approach. Journal of Family Health Care. 2009:19(3):86-9.

40. Ronicle J, Kendall S. Improving support for young carers: family focused approaches. In: Research Report DFE-RR084. United Kingdom: York Consulting LLP; 2011.

41. Jurczyk K, Lange A, Thiessen B. Doing Family, Warum Familienleben heute nicht mehr selbstverständlich ist. Weinheim: Beltz Juventa; 2014.

42. Nagl-Cupal M, Daniel M, Hauprich J: Kinder und Jugendliche als pflegende Angehörige: Einblick in die Situation Betroffener und Möglichkeiten der Unterstüzung; Teil 2: Konzeptentwicklung und Planung von familienorientierten Unterstützungsmaßnahmen für Kinder und Jugendliche als pflegende Angehörige. In., vol. (Sozialpolitische Studienreihe 19). Vienna, Austria: ÖGB-Verlag; 2015.

Submit your next manuscript to BioMed Central and we will help you at every step:

- We accept pre-submission inquiries

- Our selector tool helps you to find the most relevant journal

- We provide round the clock customer support

- Convenient online submission

- Thorough peer review

- Inclusion in PubMed and all major indexing services

- Maximum visibility for your research

Submit your manuscript at www.biomedcentral.com/submit 